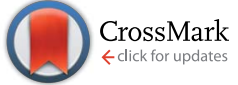

Cite this: RSC Adv., 2017, 7, 669

\title{
Using aminopyrine as a nitrogen-enriched small molecule precursor to synthesize high-performing nitrogen doped mesoporous carbon for catalyzing oxygen reduction reaction
}

\author{
Enguang Zhang, ${ }^{a}$ Mingjie Wu, ${ }^{a}$ Qiaowei Tang, ${ }^{a}$ Qiaojuan Gong, ${ }^{\text {bb }}$ Shuhui Sun, ${ }^{* c}$ \\ Jinli Qiao*a and Lei Zhang ${ }^{* d}$
}

\begin{abstract}
With aminopyrine as a nitrogen-enriched small molecule precursor, a series of nitrogen doped carbon materials have been fabricated and explored as electrocatalysts for oxygen reduction reaction (ORR). The most active catalyst is a nitrogen doped carbon, which was prepared through a facile template-mediated pyrolyzing method using ferric nitrate $\left(\mathrm{Fe}\left(\mathrm{NO}_{3}\right)_{3} \cdot 9 \mathrm{H}_{2} \mathrm{O}\right)$ as an activation reagent along with nanoscaled silica as a sacrificial support (hereafter referred to as $\mathrm{AP} / \mathrm{SiO}_{2}$ ). The $\mathrm{AP} / \mathrm{SiO}_{2}$ is confirmed and identified as having highly active molecule catalytic centers for ORR, due to its possessing a porous, sponge-like and uniform structure with a super-large specific surface area of $932.68 \mathrm{~m}^{2} \mathrm{~g}^{-1}$. The $\mathrm{AP} / \mathrm{SiO}_{2}$ catalyst exhibited a high onset potential of $0.98 \mathrm{~V}$, a half-wave potential of $0.82 \mathrm{~V}$, and a high number of exchanged electrons (>3.8, close to four) in alkaline media. After 5000 continuous cycles, the material showed almost no negative shift with respect to the $\mathrm{Pt} / \mathrm{C}$ material. Even in acidic medium, the $\mathrm{AP} / \mathrm{SiO} 2$ catalyst still showed much higher durability than $\mathrm{Pt} / \mathrm{C}$ and a low yield of $\mathrm{HO}_{2}{ }^{-}$. This work may have provided a new and simple route in the design and batch-synthesis of highly active and durable carbonaceous electrocatalysts for ORR.
\end{abstract}

Received 12th October 2016 Accepted 4th November 2016 DOI: $10.1039 / \mathrm{c} 6 \mathrm{ra} 25125 \mathrm{k}$

www.rsc.org/advances efficiently catalyze the ORR, Pt-based materials are widely recognized as the superior ORR electrocatalysts. However, the commercial applications of the Pt-based materials have been blocked by the low performance and high electrode costs of the Pt cathode. ${ }^{9,10}$ Furthermore, Pt-based catalysts are easily subject to aggregation, dissolution, and poisoning, bring down the active surface area and increasing the overpotential for fuel cell reactions, especially for the sluggish but critical ORR. ${ }^{11,12}$ So essentially, to replace the Pt materials, intensive research has been exploring by developing new ORR electrocatalyst alternatives of low-cost and abundant materials with high activity and stability. ${ }^{13}$

Cheap, efficient and abundant non-precious metal catalysts are believed to be the best long-term, sustainable solutions for large-scale applications in the fuel cell field., ${ }^{4,1415}$ In this regard, two traditional methods are normally proposed: (1) dope some heteroatoms to increase active sites using the direct pyrolysis; and (2) change the catalysts' morphology such as porous structure and size to transport properties of the ORR-relevant species. In the numerous catalysts studied, transition metal nitrogen $(\mathrm{N})$ doped carbon materials ${ }^{16,17}$ (carbon nanotubes, graphene and amorphous activated carbon), with high activity and good stability in alkaline medium have been explored as promising candidates. ${ }^{7,18,19}$ And these carbon materials may work together with the metal species, providing significantly 
promotion in catalyzing efficiency. ${ }^{\mathbf{2 0 , 2 1}}$ Recently, certain types of heteroatom doped carbon materials with N, B, S, P, Co, Fe, Mn, have shown high activity for the ORR, especially for nitrogenand sulfur-doped carbon materials. ${ }^{\mathbf{1 4 , 2 2 - 2 8}}$ It was found that the morphology of the catalyst's pores could significantly impact catalytic ORR performances besides the chemical compositions of the active sites, ${ }^{29-31}$ since pores with adequate size had a large accessible surface area, which would expose more active sites to the surrounding media, offering more and more efficient transport path for the target reactants and products. ${ }^{32}$ Therefore, it is essential to control both the morphology and structures of the catalysts. ${ }^{33}$

It is believed that the high surface area, the high porosity and the proper pore structure of catalysts usually lead to a high catalytic activity for the ORR. Herein, we present a nitrogen (N) doped mesoporous carbon material with low cost, high surface area and high porosity. The mesoporous carbon materials were synthesized by homogeneously dispersing iron and aminopyrine precursors onto the surface of the $\mathrm{SiO}_{2}$ template $\left(\mathrm{AP} / \mathrm{SiO}_{2}\right)$. In particular, we used a nitrogen-enriched small molecule precursor acting as carbon-nitrogen co-source without any additional $\mathrm{N}$ precursors. The nanoscaled silica was removed by excess amount of sodium hydroxide instead of hydrofluoric acid. Therefore, the product can be produced readily in large green quantities. Transition metal Fe was also removed by acidleaching after heat-treatment to obtain final catalysts and, thus to improve the durability of catalysts at the same time. The asprepared $\mathrm{AP} / \mathrm{SiO}_{2}$ showed a sponge-like uniform structure with a specific surface area of $932.68 \mathrm{~m}^{2} \mathrm{~g}^{-1}$. As a result, the sample exhibited outstanding ORR activity and stability both in acidic and alkaline solutions, making it a promising substitute to commercial Pt/C in both fuel cell and metal-air battery systems.

\section{Experimental}

\subsection{Catalyst preparation}

Mesoporous silica (500 $\mathrm{nm}$ particle size) was purchased from Hangzhou Wan Jing New Material Co., Ltd. Ferric nitrate $\left(\mathrm{Fe}\left(\mathrm{NO}_{3}\right)_{3} \cdot 9 \mathrm{H}_{2} \mathrm{O}\right)$, perchloric acid $\left(\mathrm{HClO}_{4}\right)$, potassium hydroxide $(\mathrm{KOH})$, aminopyrine and isopropyl alcohol were purchased from Sinopharm Chemical Reagent Co., Ltd. Sodium hydroxide $(\mathrm{NaOH})$ was purchased from Pinghu Chemical Reagent Factory. Sulfuric acid $\left(\mathrm{H}_{2} \mathrm{SO}_{4}\right)$ was purchased from Kunshan crystal microelectronics materials co., Ltd. All the chemicals were used as received without further purification.

The template $\mathrm{SiO}_{2}$ solution was prepared as we reported recently. ${ }^{25}$ The $\mathrm{AP} / \mathrm{SiO}_{2}$ was synthesized by homogeneously dispersing iron and aminopyrine precursors onto the surface of the $\mathrm{SiO}_{2}$ template. For obtaining the mesoporous carbon materials, at first, 4 grams of $\mathrm{SiO}_{2}$ were added into $40 \mathrm{~mL} 1 \mathrm{M}$ $\mathrm{HCl}$ under stirring to form a homogeneous solution. In a typical synthesis process, $100 \mathrm{~mL} 0.15 \mathrm{M}$ aminopyrine solution was added into the pre-synthesized $\mathrm{SiO}_{2}$ solution under magnetic stirring, resulting in the spontaneous coating of adherent aminopyrine layers. Then, $20 \mathrm{~mL} 0.55 \mathrm{M} \mathrm{Fe}\left(\mathrm{NO}_{3}\right)_{3}$ solution was added into this mixture under stirring for more than $1 \mathrm{~h}$. Then the viscous solution obtained above was dried for $48 \mathrm{~h}$ at $85{ }^{\circ} \mathrm{C}$.
The resulted solid was forced ground until to a homogeneous fine powder in an agate mortar, and then pyrolyzed at $800{ }^{\circ} \mathrm{C}$ under a nitrogen atmosphere for $1 \mathrm{~h}$, with a temperature ramp rate of $5{ }^{\circ} \mathrm{C} \mathrm{min}^{-1}$. Excess amount of sodium hydroxide $(\mathrm{NaOH})$ (5 M) solution were used to leach out the $\mathrm{SiO}_{2}$ for 48 hours. The resulting powder was washed with deionized water for neutralization, and then dried overnight. The redundant phase (mainly unreacted metallic iron and iron compounds) were removed, using acid-leached with $0.5 \mathrm{M} \mathrm{H}_{2} \mathrm{SO}_{4}$ at $85{ }^{\circ} \mathrm{C}$ for $8 \mathrm{~h}$, then re-pyrolyzed at $800{ }^{\circ} \mathrm{C}$ for $1 \mathrm{~h}$ under the same conditions as those during the first heat treatment to obtain the final catalyst sample.

To confirm the effect of specific surface area and pore structure, two other samples were also synthesized: one is the VulcanBP2000 carbon black (provided by Carbot Corporation with a specific surface area of $1475 \mathrm{~m}^{2} \mathrm{~g}^{-1}$ ), which was used as the support to increase the conductivity and specific surface area, thus denoted as AP/BP2000. The other one was AP, which was also synthesized as general catalyst but without any addition of $\mathrm{SiO}_{2}$ template or carbon support, just simply pyrolyzed under the same high temperature as for $\mathrm{AP} / \mathrm{SiO}_{2}$ and $\mathrm{AP} / \mathrm{BP} 2000$.

\subsection{Sample characterization}

Scanning electron microscopy (SEM) analysis was carried out using HITACHI/S-4800 system. Transmission electron microscopy (TEM) analyses were carried out using a high-resolution Hitachi JEM-2100 system operating at $200 \mathrm{kV}$. To verify the microstructures of the samples, XRD patterns were collected by a Rigaku D/max-2550 V diffractometer with $\mathrm{Cu} \mathrm{K \alpha}$ radiation operating at $30 \mathrm{kV}$ and $40 \mathrm{~mA}$. The specific surface area was measured by the Brunauer-Emmett-Teller (BET) method using nitrogen adsorption-desorption isotherms on an ASAP 2020 volumetric adsorption analyzer (Micromeritics, U.S.A.), and the specific surface area was in a relative pressure range of 0.05-0.3. The pore size distribution curves were calculated by the nonlocal density functional theory. X-ray photoelectron spectroscopy (XPS) measurements were performed to analyze surface particles of the catalyst, using a spectrometer (RBDupgraded PHI-5000C ECSA system (PerkinElmer)) with an Al $\mathrm{K} \alpha \mathrm{X}$-ray anode source $(h \nu=1486.6 \mathrm{eV})$ at $14.0 \mathrm{kV}$ and $250 \mathrm{~W}$.

\subsection{Electrochemical measurements}

All of the electrochemical measurements were performed using a standard three-electrode cell with the CHI Electrochemical Station (760D). The electrocatalytic activities were evaluated by linear sweep voltammetry (LSV) using both rotating disk electrode (RDE) and rotating ring-disk electrode (RRDE) techniques using a Pine RDE instrument (Pine Research Instrumentation, USA). A platinum wire was used as the counter electrode and a saturated calomel electrode as the reference electrode, respectively. The catalyst of $5.0 \mathrm{mg}$ was dispersed in a $1 \mathrm{~mL}$ mixed solution containing $800 \mu \mathrm{L}$ isopropyl alcohol and $200 \mu \mathrm{L}$ $0.5 \%$ Nafion (diluted with methanol) to prepare the catalyst ink (ultrasonically mixing for more than $1 \mathrm{~h}$ ). Then $5 \mu \mathrm{L}$ (loading, $100 \mu \mathrm{g} \mathrm{cm}^{-2}$ ) or $15 \mu \mathrm{L}$ (loading, $300 \mu \mathrm{g} \mathrm{cm}^{-2}$ ) of ink was applied onto a clean glassy carbon (GC) disk (6.25 $\mathrm{mm}$ inner diameter 
and $7.92 \mathrm{~mm}$ outer diameter) with a sectional area of 0.2475 $\mathrm{cm}^{2}$ and used as the working electrode. For comparison, a commercially available $\mathrm{Pt} / \mathrm{C}$ catalyst (20 wt $\% \mathrm{Pt}$ ) was used as the baseline. Pt/C catalyst (loading, $100 \mu \mathrm{g} \mathrm{cm}^{-2}$ ) was also measured under the same conditions. All electrochemical tests were performed in $\mathrm{O}_{2}$-saturated $0.1 \mathrm{M} \mathrm{KOH}$ at room temperature. A flow of $\mathrm{O}_{2}$ was maintained over the electrolyte to ensure a continuous $\mathrm{O}_{2}$ saturation during the measurement. In this work, all potentials were converted to the reversible hydrogen electrode (RHE) scale using the well-known Nernst relation, $E$ $(\mathrm{RHE})=E(\mathrm{SHE})+0.059 \mathrm{pH}$. Before each measurement, the electrolyte was bubbled with $\mathrm{O}_{2}$ for 30 minutes. Linear sweep voltammetry was conducted under the same conditions in an $\mathrm{N}_{2}$-saturated electrolyte to subtract the background capacitive current.

\section{Results and discussion}

\subsection{Physical characterization}

The morphology and microstructure were first investigated by means of scanning electron microscopy (SEM) and lowresolution transmission electron microscopy (TEM). As shown in Fig. 1(a)-(c), AP demonstrated a sheet-like structure, whereas AP/BP2000 showed a particle cluster structure. This may derive from the specific morphology features (high surface area and coarse structure) of BP2000. It was worthwhile to note that sponge-like uniform structure was observed for the $\mathrm{AP} / \mathrm{SiO}_{2}$ catalyst, obviously from the removing of $\mathrm{SiO}_{2}$. The TEM images shown in Fig. 1(d)-(f) reflected the geometric characteristics of the AP without any template and demonstrated successful introduction of BP2000 and $\mathrm{SiO}_{2}$ for these catalysts. The XRD pattern of $\mathrm{AP} / \mathrm{SiO}_{2}$ (Fig. 2(a)) showed only two apparent broad diffraction peaks $\left(23^{\circ}\right.$ and $\left.43^{\circ}\right)$, which correspond to the (002) and (004) planes of carbon materials with low graphitization, certifying an entirely amorphous structure. Obviously, this structure was consistent with the sponge-like structure shown in Fig. 1(f). In addition, we could hardly observe any metalcontaining nanoparticles by TEM inspection because the etching processes dissolved both the inorganic template silica and metal particles, which are also proved by XRD pattern.

In view of the surface properties, XPS was conducted to study the surface chemical composition of the samples. The XPS data confirmed the presence of $\mathrm{N}$ in the carbonized products (AP, $\mathrm{AP} /$ $\mathrm{BP} 2000$ and $\left.\mathrm{AP} / \mathrm{SiO}_{2}\right)$. The elemental analysis results were also
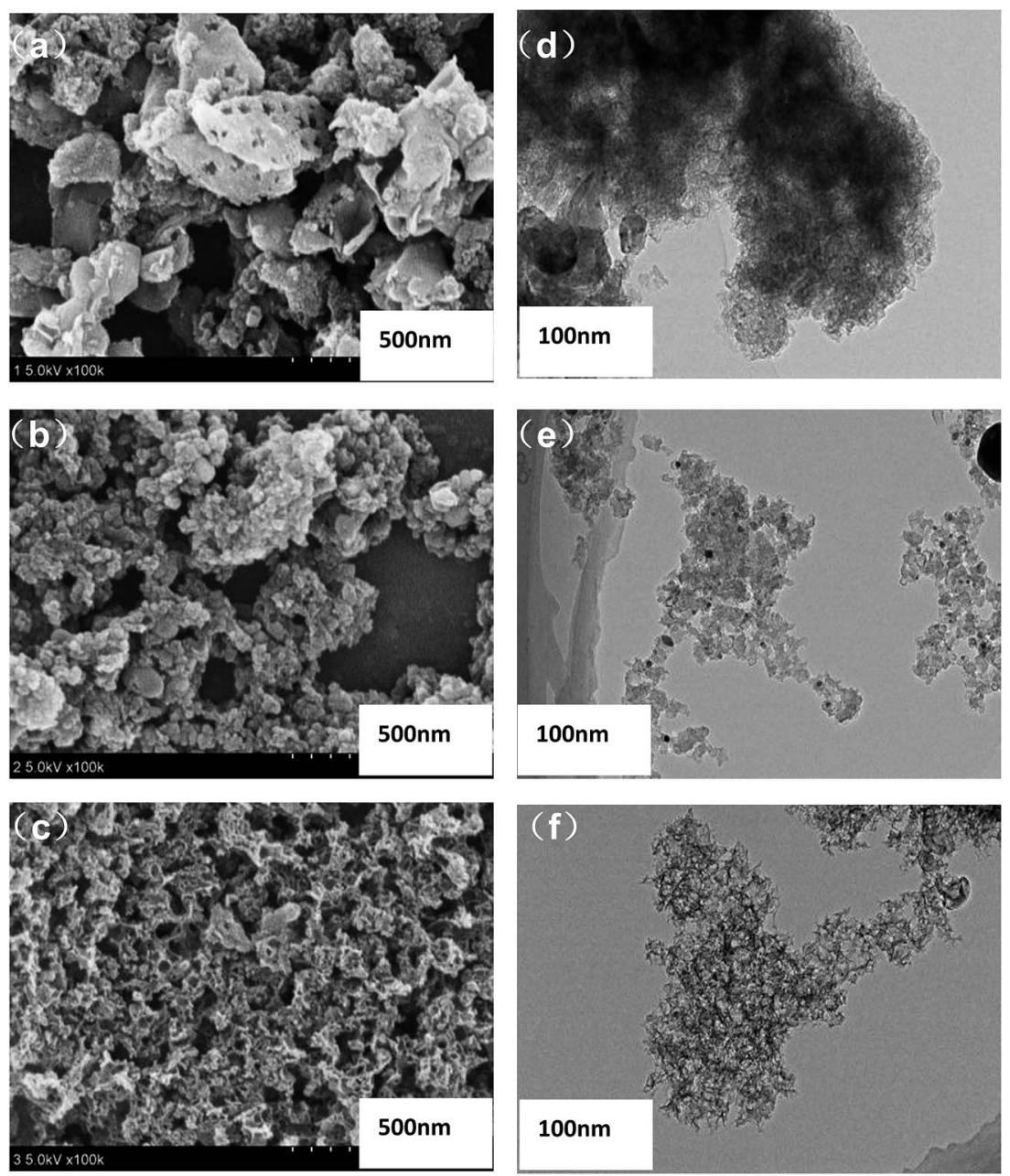

Fig. 1 SEM images of AP (a), AP/BP2000 (b), and AP/SiO 2 (c). TEM images of as-prepared AP (d), AP/BP2000 (e), and AP/SiO 2 (f). 

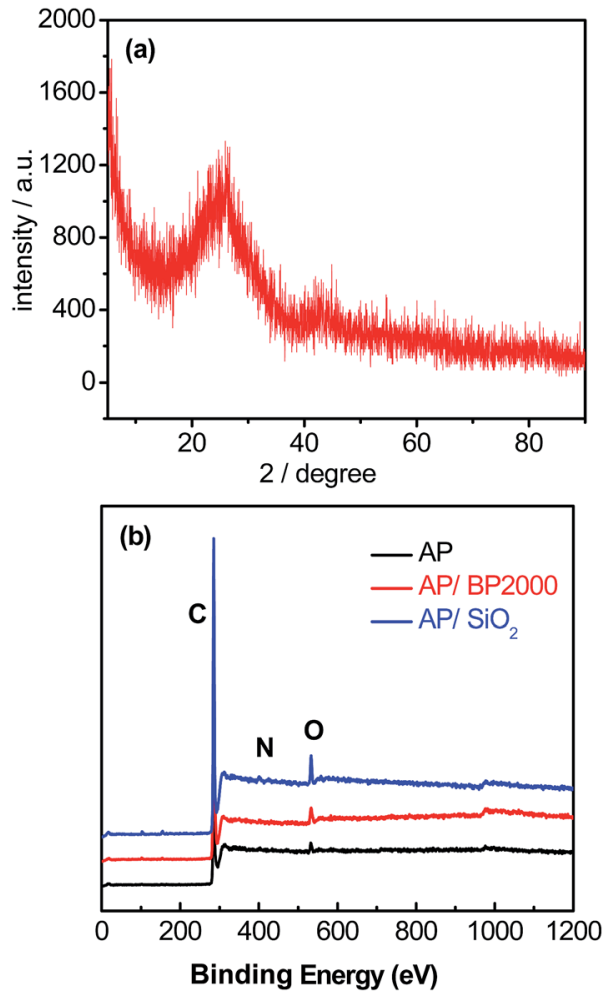

Fig. 2 (a) XRD pattern of $\mathrm{AP} / \mathrm{SiO}_{2}$ sample. (b) XPS spectra of AP, AP/ $\mathrm{BP} 2000$, and $\mathrm{AP} / \mathrm{SiO}_{2}$ catalyst samples.

shown in Table 1. As shown in Fig. 2(b), almost no silica or metallic species can be detected for all of the three samples except for C, N, O signals. Obviously, this result may not be accurate enough to prove that the leaching processes using $\mathrm{NaOH}$ solution and $\mathrm{H}_{2} \mathrm{SO}_{4}$ are extremely effective. Therefore, we made further elemental analysis using ICP technique, and found that the final Fe content of catalysts was around $0.4 \mathrm{wt} \%$. This result confirmed the presence of trace metals, which was consistent with those reported elsewhere. ${ }^{14,24-28}$ Therefore, we could not completely rule out the contribution of residual $\mathrm{Fe}$ to the ORR performance in this work, although the content of Fe is very low. By curve-fitting the high-resolution $\mathrm{N}$ 1s spectrum of AP (Fig. 3(a)), three different components of nitrogen could be proposed as pyridinic- $N$ at $398.4 \mathrm{eV}$, pyrrolic- $N$ at $399.7 \mathrm{eV}$ and graphitic- $N$ at $401.1 \mathrm{eV} \cdot{ }^{34}$ It was noteworthy that the $\mathrm{N}$ 1s spectra of AP/BP2000 (Fig. 3(b)) and $\mathrm{AP} / \mathrm{SiO}_{2}$ (Fig. 3(c)) showed only two different signals having binding energies of $398.4 \mathrm{eV}, 401.1 \mathrm{eV}$, corresponding to pyridinic- $N$ and graphitic$N$, respectively. To the best of our knowledge pyridinic- $N$ and
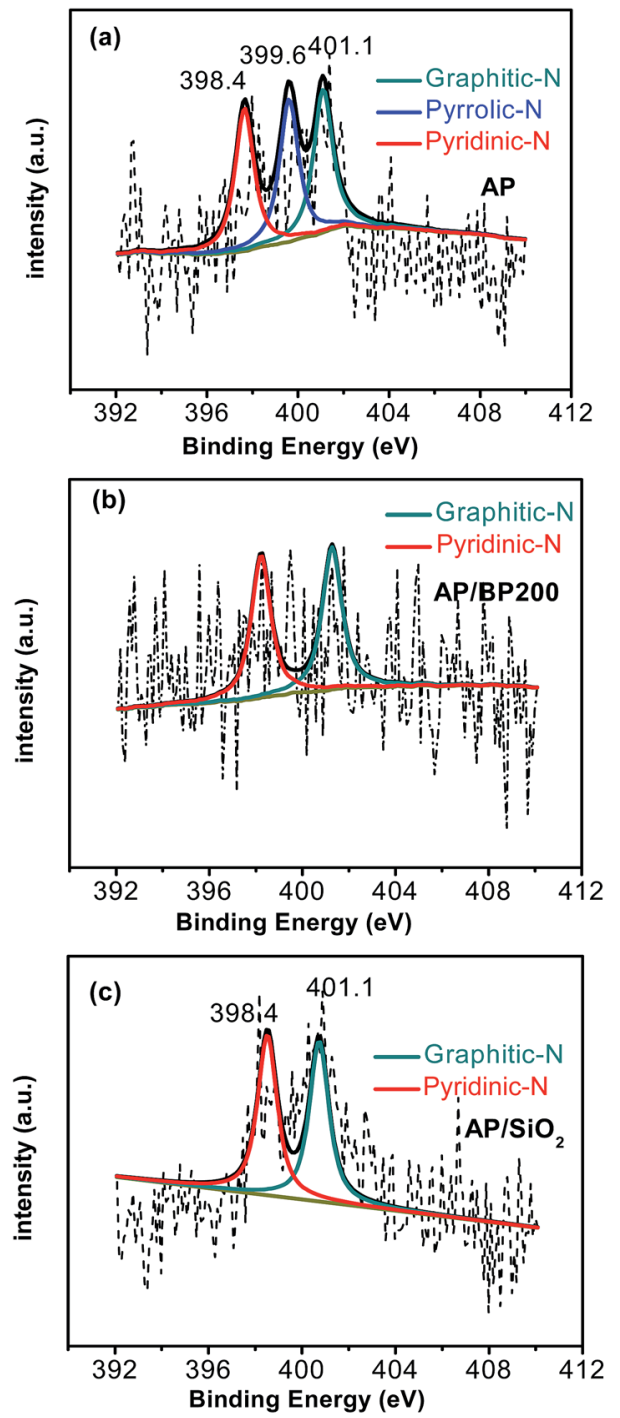

Fig. 3 High-resolution N 1s XPS spectra of AP (a), AP/BP2000 (b), and $\mathrm{AP} / \mathrm{SiO}_{2}$ (c).

graphitic- $N$ are generally believed to participate in the active sites. ${ }^{35-37}$ This phenomena was also found in our most recently reported work derived from nitrogen-enriched polyquaternium $^{\mathbf{2 4 , 2 5}}$ and poly(ethyleneimine). ${ }^{\mathbf{1 4}}$ The ratio of different functions nitrogen of the total nitrogen was shown in Table 1 . This may verify that the low ORR catalytically active form of pyrrolic- $N$ was found to be the dominant form of the doped $\mathrm{N}$ for AP, while the pyridinic- $N$ and graphitic- $N$ with high ORR catalytic activity for $\mathrm{AP} / \mathrm{SiO}_{2} \cdot{ }^{38,39}$

Table 1 Elemental analysis results from XPS

\begin{tabular}{|c|c|c|c|c|c|}
\hline Catalysts & $\begin{array}{l}\text { Total surface } \\
\text { C content (at\%) }\end{array}$ & \multicolumn{3}{|c|}{ Surface content (at\%) of different $\mathrm{N}$ functionalities } & $\begin{array}{l}\text { Total surface } \\
\text { O content (at } \%)\end{array}$ \\
\hline $\mathrm{AP} / \mathrm{BP} 2000$ & $44.88 \%$ & $2.75 \%$ & $2.90 \%$ & - & $49.47 \%$ \\
\hline $\mathrm{AP} / \mathrm{SiO}_{2}$ & $40.56 \%$ & $3.84 \%$ & $4.34 \%$ & - & $51.26 \%$ \\
\hline
\end{tabular}


The porous nature of the three catalysts was assessed by nitrogen adsorption-desorption analysis (Fig. 4(a)-(c)). Both the AP and AP/BP2000 catalysts exhibited gentle isotherm, while AP/ $\mathrm{SiO}_{2}$ showed a steep increase of nitrogen absorption at a relatively high pressure. As a result, the existence of mesopores was testified. The nitrogen adsorption-desorption analysis proved that the porous structures are consistent with the SEM and TEM
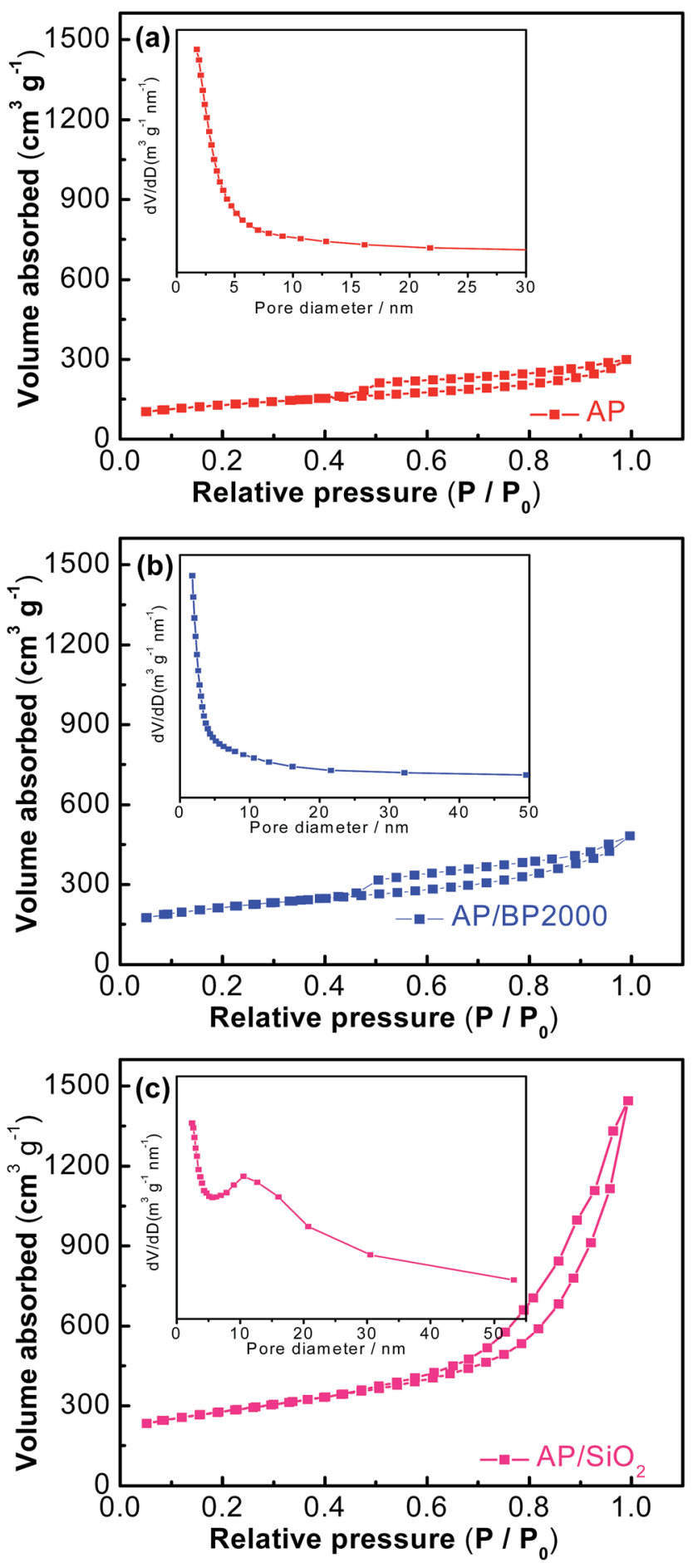

Fig. $4 \mathrm{~N}_{2}$ sorption isotherms of $\mathrm{AP}(\mathrm{a}), \mathrm{AP} / \mathrm{BP} 2000$ (b), and $\mathrm{AP} / \mathrm{SiO}_{2}$ (c). Insets show the pore size distribution from the $\mathrm{BJH}$ method of corresponding samples. images. The BET surface areas of these three catalysts are 434.4 $\mathrm{m}^{2} \mathrm{~g}^{-1}$ (AP), $708.4 \mathrm{~m}^{2} \mathrm{~g}^{-1}$ (AP/BP2000), and $932.7 \mathrm{~m}^{2} \mathrm{~g}^{-1}$ (AP/ $\mathrm{SiO}_{2}$ ), respectively, where the $\mathrm{AP} / \mathrm{SiO}_{2}$ shows the largest surface area. It is obvious that the porous structure in $\mathrm{AP}$ and $\mathrm{AP} /$ BP2000 are not observed, whereas the mesopore size distribution is clearly centered at $12.5 \mathrm{~nm}$ for $\mathrm{AP} / \mathrm{SiO}_{2}$, according to the Barrett-Joyner-Halenda (BJH) model (inset in Fig. 4(c)).

\subsection{Electrochemical measurements}

The ORR performance of $\mathrm{AP}, \mathrm{AP} / \mathrm{BP} 2000$ and $\mathrm{AP} / \mathrm{SiO}_{2}$ were investigated, using both the cyclic voltammetry (CV) and the linear sweep voltammetry (LSV) on a rotating disk electrode (RDE). Fig. 5(a) showed the $\mathrm{CV}$ curves of $\mathrm{AP} / \mathrm{SiO}_{2}$ and $20 \% \mathrm{Pt} / \mathrm{C}$, tested in a $\mathrm{N}_{2}$ - and $\mathrm{O}_{2}$-saturated $0.1 \mathrm{M} \mathrm{KOH}$ aqueous electrolyte solution at a scan rate of $50 \mathrm{mV} \mathrm{s}^{-1}$. In conditions of the $\mathrm{O}_{2}$ saturated solution, the $\mathrm{CV}$ curves both exhibited significant cathodic oxygen reduction peaks, whereas the $\mathrm{CV}$ curves showed no obvious peaks in the $\mathrm{N}_{2}$-saturated electrolyte. Compared with $20 \% \mathrm{Pt} / \mathrm{C}, \mathrm{AP} / \mathrm{SiO}_{2}$ displayed almost the same pronounced ORR peak with potential $0.85 \mathrm{~V}$ vs. $0.84 \mathrm{~V}$, and a higher corresponding current density. The results strongly certified that the $\mathrm{AP} / \mathrm{SiO}_{2}$ had good ORR catalytic performance towards ORR relatively.

To gain further insight into the ORR, RDE technique was performed in $\mathrm{O}_{2}$ - saturated $0.1 \mathrm{M} \mathrm{KOH}$ aqueous solution with a scan rate of $5 \mathrm{mV} \mathrm{s}^{-1}$. Fig. 5(b) compared the RDE polarization curves obtained at $1600 \mathrm{rpm}$ for the catalysts. As shown in Fig. 5(b), the LSV curves of pure AP in $0.1 \mathrm{M} \mathrm{KOH}$ was sluggish. The sharp increase in onset potential relative to AP indicated that the addition of $\mathrm{BP} 2000$ and $\mathrm{SiO}_{2}$ improved the electrocatalytic activity greatly. The onset potential reflects the $\mathrm{O}_{2}$ reduction overpotential. This implies that the larger BET surface area may lead to the better ORR performance. For comparison, $20 \% \mathrm{Pt} / \mathrm{C}$ was also obtained in a similar way, and the onset potential of $0.96 \mathrm{~V}$ was observed. The onset potential, half potential and current density of the catalysts are shown in Table 2. Evidently, the $\mathrm{AP} / \mathrm{SiO}_{2}$ exhibits a comprehensive advantage over the other two catalysts. To our interest, the AP/ $\mathrm{SiO}_{2}$ electrode with a loading of $300 \mu \mathrm{g} \mathrm{cm}^{-2}$ possessed an onset potential of $0.98 \mathrm{~V}$, even more positive than that of the $20 \% \mathrm{Pt} / \mathrm{C}$ electrode (0.96 V) (Fig. 5(b)). Compared to $20 \% \mathrm{Pt} / \mathrm{C}$, the $\mathrm{AP} / \mathrm{SiO}_{2}$ gives higher onset potential (about $0.02 \mathrm{~V}$ ), larger current

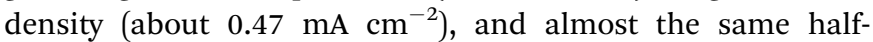
potential at $0.82 \mathrm{~V}$ (shown in Table 2). The activity of the catalyst is as good as most of catalysts reported before, ${ }^{\mathbf{4 0}}$ and even much higher than these catalysts. ${ }^{\mathbf{4 1 - 4 3}}$ The excellent performance of $\mathrm{AP} / \mathrm{SiO}_{2}$ derived from the structural features such as larger specific surface area and suitable porous structure. In short, the ORR performance of $\mathrm{AP} / \mathrm{SiO}_{2}$ was higher than commercial Pt/C, which opened up a new path for the fuel cells.

The kinetic process and pathway of the ORR on $\mathrm{AP} / \mathrm{SiO}_{2}$ electrode was thoroughly evaluated using diffusion-corrected Tafel plots. Polarization curves of the $\mathrm{AP} / \mathrm{SiO}_{2}$ catalyst at different rotation rates $(300,600,900,1200$ and $1600 \mathrm{rpm})$, were recorded using the RDE technique (Fig. 5(c)). The curves showed an increase in the catalytic current density with rotation 

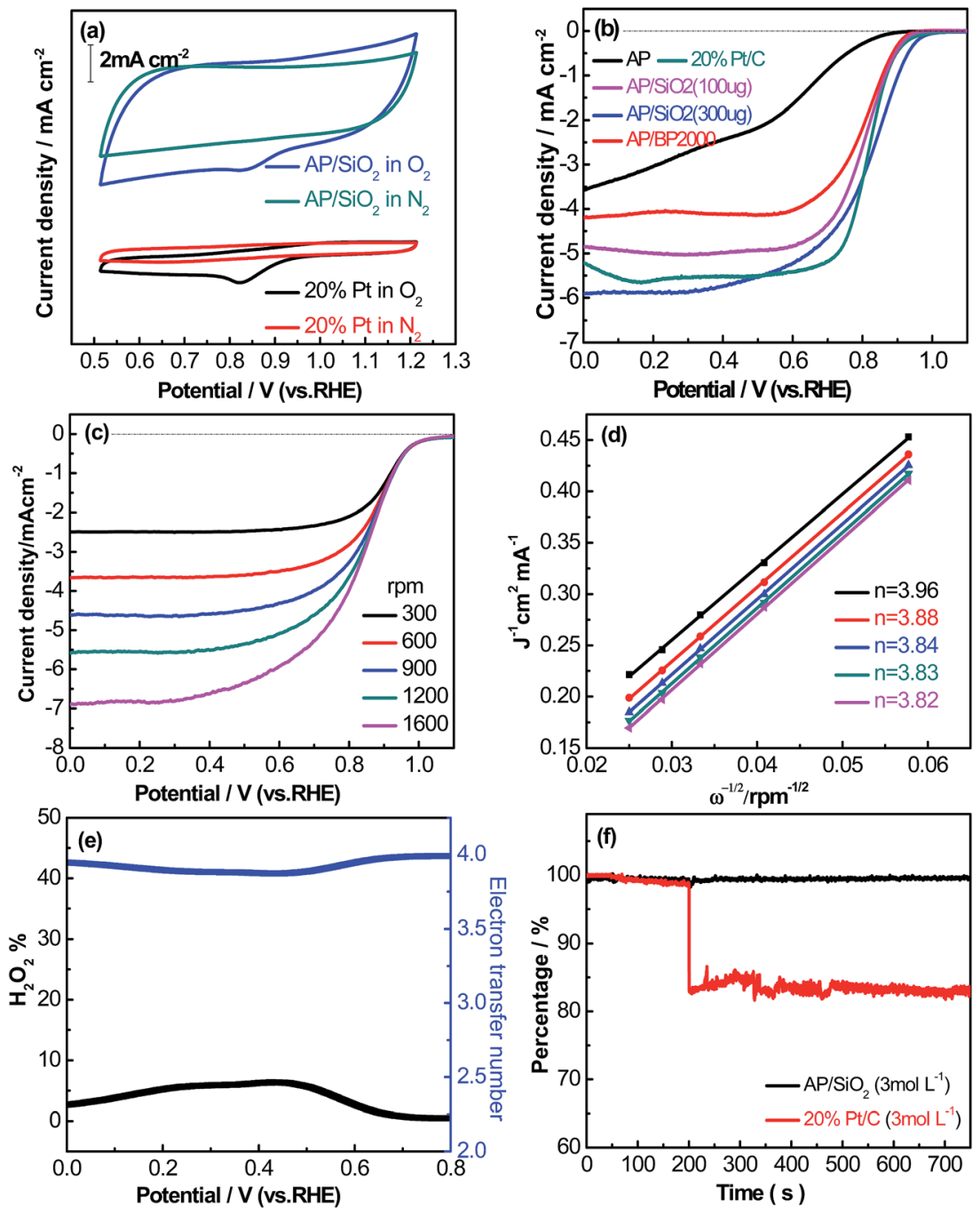

Fig. 5 (a) Cyclic voltammograms of $\mathrm{AP} / \mathrm{SiO}_{2}, 20 \% \mathrm{Pt}$ in $\mathrm{N}_{2}$ - and $\mathrm{O}_{2}$-saturated $0.1 \mathrm{M} \mathrm{KOH}$ at a scan rate of $50 \mathrm{mV} \mathrm{s}$. (b) Linear sweep voltammograms (LSVs) of various electrocatalysts on a rotating disk electrode (1600 rpm) in $\mathrm{O}_{2}$-saturated $0.1 \mathrm{M} \mathrm{KOH}$ at a scan rate of $5 \mathrm{mV} \mathrm{s}{ }^{-1}$. (c) Polarization curves of $\mathrm{AP} / \mathrm{SiO}_{2}$ in $\mathrm{O}_{2}$-saturated $0.1 \mathrm{M} \mathrm{KOH}$ at different rotation rates. (d) Koutecky-Levich plots at different electrode potential. (e) RRDE LSV along with $\mathrm{H}_{2} \mathrm{O}_{2}$ yields of $\mathrm{AP} / \mathrm{SiO}_{2}$ electrode (1600 rpm) in $0.1 \mathrm{M} \mathrm{KOH}$ at a scan rate of $5 \mathrm{mV} \mathrm{s}^{-1}$. (f) Chronoamperometric responses of $\mathrm{AP} / \mathrm{SiO}_{2}$ and $\mathrm{Pt} / \mathrm{C}$ coated electrodes measured in $\mathrm{O}_{2}$-saturated $0.1 \mathrm{M} \mathrm{KOH}$ with $3 \mathrm{M}$ methanol added.

rates because of the enhanced diffusion of electrolytes. ${ }^{37}$ Then the Koutecky-Levich plots for the ORR at different potential for $\mathrm{AP} / \mathrm{SiO}_{2}$ can be obtained. The slope of the plots allowed us to check the consistency with the theoretical values according to the following eqn (1):

Table 2 Electrochemical data obtained from cyclic and linear sweep voltammetries in $\mathrm{O}_{2}$ saturated $0.1 \mathrm{M} \mathrm{KOH}$ for AP, AP/BP2000 and AP/ $\mathrm{SiO}_{2}$

\begin{tabular}{lllll}
\hline Catalysts & $\begin{array}{l}\text { Loading } \\
\left(\mu \mathrm{c} \mathrm{cm}^{-2}\right)\end{array}$ & $\begin{array}{l}\text { Onset potential } \\
(V \text { vs. RHE })\end{array}$ & $\begin{array}{l}\text { Half-potential } \\
(V \text { vs. RHE })\end{array}$ & $\begin{array}{l}\text { Current density } \\
(V \text { vs. RHE })\end{array}$ \\
\hline $\mathrm{AP}$ & 300 & 0.86 & 0.58 & 3.58 \\
$\mathrm{AP} / \mathrm{BP} 2000$ & 300 & 0.93 & 0.81 & 4.21 \\
$\mathrm{AP} / \mathrm{SiO}_{2}$ & 100 & 0.94 & 0.80 & 4.85 \\
$\mathrm{AP} / \mathrm{SiO}_{2}$ & 300 & 0.98 & 0.82 & 5.97 \\
$20 \% \mathrm{Pt} / \mathrm{C}$ & 100 & 0.96 & 0.82 & 5.50
\end{tabular}

$$
\frac{1}{j}=\frac{1}{j_{\mathrm{k}}}+\frac{1}{j_{\mathrm{f}}}+\frac{1}{j_{\mathrm{d}}}
$$

where $j$ was the measured current density at given potential, $j_{\mathrm{k}}$ was the activation controlled current density, $j_{\mathrm{f}}$ was the influence of Nafion ionomer within the catalyst layer on the measured current density, and $j_{\mathrm{d}}$ was the $\mathrm{O}_{2}$ diffusion limiting current density. Due to the $j_{\mathrm{f}}$ may note if the equivalent Nafion ionomer thickness was much small $\left(j_{\mathrm{f}} \rightarrow \infty\right)$, therefore, the reciprocal of $j_{\mathrm{f}}$ can be negligible. Under this circumstance, the eqn (1) can be simplified to eqn (2):

$$
\frac{1}{j}=\frac{1}{j_{\mathrm{k}}}+\frac{1}{j_{\mathrm{d}}}
$$

The $j_{\mathrm{d}}$ can be expressed as eqn (3):

$$
j_{\mathrm{d}}=0.2 n F C_{\mathrm{O}_{2}} D_{\mathrm{O}_{2}} \frac{2}{3} v^{-\frac{1}{6}} w^{\frac{1}{2}}
$$


where $n$ was the overall electron transfer number per molecule of $\mathrm{O}_{2}$ reduced, $w$ stood for the electrode rotation rate (rpm), $F$ represented the Faraday's constant $\left(F=96485 \mathrm{C} \mathrm{mol}^{-1}\right), C_{\mathrm{O}_{2}}$ was the concentration of dissolved oxygen, $D_{\mathrm{O}_{2}}$ was choose as the diffusion coefficient of oxygen in the bulk solution, $v$ stood for the kinematic viscosity of the solution.

With $\mathrm{AP} / \mathrm{SiO}_{2}$ as a typical candidate, Fig. 5(d) showed the Koutecky-Levich plots at 0.61, 0.65, 0.69, 0.73, $0.77 \mathrm{~V}$, respectively. By computing the slopes of the Koutecky-Levich plots, the number of transferred electrons of 3.96, 3.88, 3.84, 3.83, 3.82 are figured out, which increases with a cathodically increased potential. It can be seen that the number of transferred electrons for oxygen reduction depend on the high positive over potentials with an average value of 3.86. This result demonstrates that the $4 \mathrm{e}^{-}$transfer process has taken place, and the reduction of $\mathrm{O}_{2}$ produces $\mathrm{HO}_{2}{ }^{-}$in the final product in $\mathrm{AP} /$
$\mathrm{SiO}_{2}$ electrode. This result is consistent with the description in literature. ${ }^{22,26,27,44}$ As we have described above, the final Fe content of $\mathrm{AP} / \mathrm{SiO}_{2}$ catalyst is around $0.4 \mathrm{wt} \%$. According to literature, even a slight trace of metallic impurities in carbon materials may have a strong influence on the ORR. ${ }^{14,46}$ This indicates that the groups among Fe and $\mathrm{N}$ may act as catalysts' active sites for ORR, following $4 \mathrm{e}^{-}$transfer process. On the other hand, the excellent ORR electrocatalytic performance of the $\mathrm{AP} / \mathrm{SiO}_{2}$ can be resulted from the introduction of the unique mesoporous structures. ${ }^{\mathbf{1 4 , 2 4 , 2 5}}$ This was further confirmed by a rotating ring-disk electrode (RRDE) measurement that monitors the peroxide species $\left(\mathrm{HO}_{2}{ }^{-}\right)$produced during the ORR process on the $\mathrm{AP} / \mathrm{SiO}_{2}$ catalyzed electrode.

The percentage of peroxide $\left(\mathrm{H}_{2} \mathrm{O}_{2} \%\right)$ was determined using RRDE technique at room temperature based on ring current $\left(I_{\mathrm{r}}\right)$ and the disk current $\left(I_{\mathrm{d}}\right)$ through the following eqn (4):
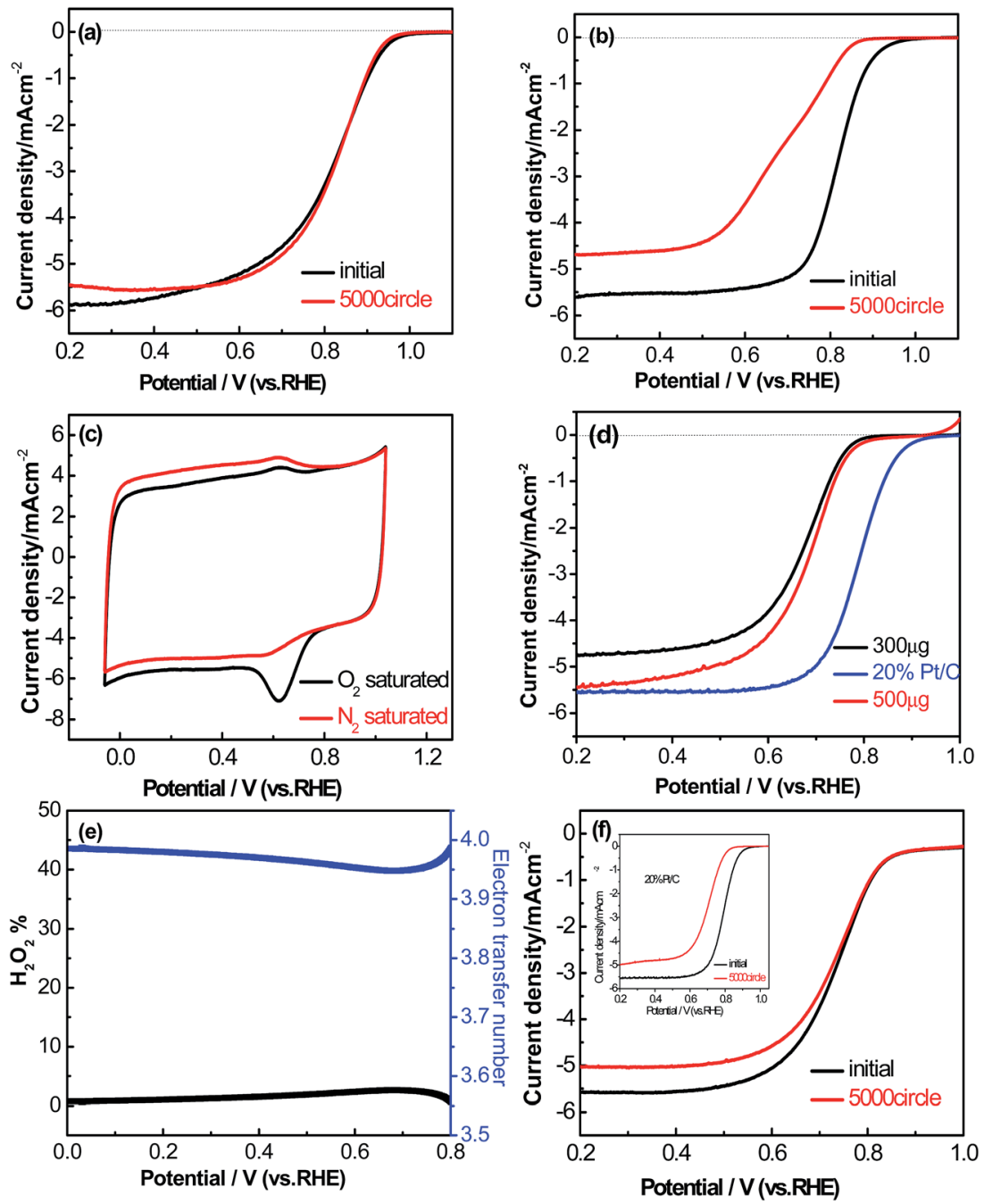

Fig. 6 Linear sweep voltammograms of (a) $\mathrm{AP}_{\mathrm{SiO}}$, (b) $20 \% \mathrm{Pt} / \mathrm{C}$ on a rotating disk electrode (1600 rpm) before and after $5000 \mathrm{cycles}$ in $\mathrm{O}_{2}-$ saturated $0.1 \mathrm{M} \mathrm{KOH}$ at a scan rate of $5 \mathrm{mV} \mathrm{s}^{-1}$. (c) Cyclic voltammograms of $\mathrm{AP} / \mathrm{SiO}_{2}$ in $\mathrm{O}_{2}$-saturated $0.1 \mathrm{M} \mathrm{KOH}$ at a scan rate of $50 \mathrm{mV} \mathrm{s}{ }^{-1}$. (d) Linear sweep voltammograms of $\mathrm{AP} / \mathrm{SiO}_{2}$ with $300 \mu \mathrm{g} \mathrm{cm}^{-2}$ and $500 \mu \mathrm{g} \mathrm{cm}^{-2}$ loadings, and Pt/C catalyst (20 wt\% Pt, loading: $100 \mu \mathrm{g} \mathrm{cm}{ }^{-2}$ ) at a scan rate of $5 \mathrm{mV} \mathrm{s}^{-1}$. Electrolyte, $0.5 \mathrm{M} \mathrm{H}_{2} \mathrm{SO}_{4}$ for $\mathrm{AP} / \mathrm{SiO}_{2}$ and $0.1 \mathrm{M} \mathrm{HClO}_{4}$ for $\mathrm{Pt} / \mathrm{C}$ (e) RRDE LSV along with $\mathrm{H}_{2} \mathrm{O}_{2}$ yields of $\mathrm{AP} / \mathrm{SiO} 2$ electrode in $0.5 \mathrm{M} \mathrm{H}_{2} \mathrm{SO}_{4}$ at a scan rate of $5 \mathrm{mV} \mathrm{s}^{-1}$. (f) Linear sweep voltammograms of $\mathrm{AP} / \mathrm{SiO}_{2}$ on a rotating disk electrode (1600 rpm) before and after 5000 cycles in $\mathrm{O}_{2}$-saturated $0.5 \mathrm{M} \mathrm{H}_{2} \mathrm{SO}_{4}$ at a scan rate of $5 \mathrm{mV} \mathrm{s}^{-1}$ (inset: the same tests of $20 \% \mathrm{Pt} / \mathrm{C}$ with loading of $100 \mu \mathrm{g} \mathrm{cm}{ }^{-2}$ ). 


$$
\mathrm{H}_{2} \mathrm{O}_{2} \%=100 \times \frac{2 I_{\mathrm{r}} / N}{I_{\mathrm{d}}+I_{\mathrm{r}} / N}
$$

The electron transfer number $(n)$ could be calculated via the following eqn (5):

$$
n=\frac{4 I_{\mathrm{d}}}{I_{\mathrm{d}}+I_{\mathrm{r}} / N}
$$

where $N$ represent the current collection efficiency of Pt ring with a value of 0.36 . In order to calibrate its value, contrast experiments were done in $0.1 \mathrm{M} \mathrm{KOH}$ with a $10 \mathrm{mM} \mathrm{K}_{3} \mathrm{Fe}(\mathrm{CN})_{6}$ electrolyte. ${ }^{47}$

As shown in Fig. 5(e), the peroxide yield on the $\mathrm{AP} / \mathrm{SiO}_{2}$ electrode was found to be less than $8 \%$ over the potential range of $0 \mathrm{~V}$ to $0.80 \mathrm{~V}$. The corresponding electron transfer number was higher than 3.8, suggesting the nearly complete reduction of oxygen to water.

Given the excellent $\mathrm{ORR}$ activity of $\mathrm{AP} / \mathrm{SiO}_{2}$, its ability to tolerance the negative effect of methanol oxidation on cathode of direct methanol fuel cells was also tested (this is important for direct methanol fuel cells, in which methanol can crossover from anode to cathode to react with ORR electrode, reducing the cathode potential, poison the ORR catalyst, and waste methanol fuel). To test the methanol tolerance of the $\mathrm{AP} / \mathrm{SiO}_{2}$ catalyst, the chronoamperometric responses was recorded in the presence of methanol in the electrolyte solution, and $20 \%$ $\mathrm{Pt} / \mathrm{C}$ as a comparison (shown in Fig. 5(f)). After the addition of $3 \mathrm{M}$ methanol to a $0.1 \mathrm{M} \mathrm{KOH}$ solution saturated with $\mathrm{O}_{2}$, it can be seen that the $\mathrm{AP} / \mathrm{SiO}_{2}$ electrode has superior ability to tolerance methanol oxidation, however, the $\mathrm{Pt} / \mathrm{C}$ showed a dramatic decrease under the same testing conditions. These results extremely indicated that the $\mathrm{AP} / \mathrm{SiO}_{2}$ catalyst also displayed a high selectivity for the ORR with excellent resistance to methanol crossover poisoning effects, besides the excellent electrocatalytic activity.

The durability of the $\mathrm{AP} / \mathrm{SiO}_{2}$ electrode was also evaluated in an $\mathrm{O}_{2}$-saturated $0.1 \mathrm{M} \mathrm{KOH}$ solution at a scan rate of $50 \mathrm{mV} \mathrm{s}^{-1}$ (Fig. 6(a)). In this regard, we tested and compared the RDE curves before and after 5000 cycles with $\mathrm{Pt} / \mathrm{C}$ catalyst as a benchmark. It was noted that after 5000 continuous cycles, there was $18 \%$ of decrease to the initial current density observed from the Pt/C electrode, and half-wave potential $E_{1 / 2}$ exhibited a severe shift of $127 \mathrm{mV}$ (Fig. 6(b)). Importantly, the $\mathrm{AP} / \mathrm{SiO}_{2}$ showed only a $7 \%$ decrease relative to the initial current density within the same tested period, and half-wave potential $E_{1 / 2}$ almost exhibited no shift (Fig. 6(a)), indicating that the $\mathrm{AP} / \mathrm{SiO}_{2}$ catalyst was very stable in alkaline solution.

To the best of our knowledge, a large part of non-precious metal catalysts possess high overpotential and low durability in acidic medium. ${ }^{45}$ The electrocatalytic performance of the $\mathrm{AP} /$ $\mathrm{SiO}_{2}$ in acidic medium $\left(0.5 \mathrm{M} \mathrm{H}_{2} \mathrm{SO}_{4}\right)$ was also investigated. As the CV curves shown in Fig. 6(c), the $\mathrm{AP} / \mathrm{SiO}_{2}$ catalyst showed an obvious peak at $0.674 \mathrm{~V} v$ s. RHE in $\mathrm{O}_{2}$-saturated $0.1 \mathrm{M} \mathrm{HClO}_{4}$ solution. The LSV measurements on RDE for each of $\mathrm{AP} / \mathrm{SiO}_{2}$ and $20 \% \mathrm{Pt} / \mathrm{C}$ in $0.1 \mathrm{M} \mathrm{HClO}_{4}$ electrolyte at a scan rate of $50 \mathrm{mV}$ $\mathrm{s}^{-1}$ and a rotation rate of $1600 \mathrm{rpm}$ were then conducted
(Fig. 6(d)). Compared with 20\% Pt/C (loading of $100 \mu \mathrm{g} \mathrm{cm} \mathrm{cm}^{-2}$ ), the $\mathrm{AP} / \mathrm{SiO}_{2}$ with a loading of $300 \mu \mathrm{g} \mathrm{cm} \mathrm{cm}^{-2}$, showed a relatively small onset potential at $0.79 \mathrm{~V} v s$. RHE, half potential at $0.66 \mathrm{~V}$, and current density $4.8 \mathrm{~mA} \mathrm{~cm} \mathrm{~cm}^{-2}$, but with the increase of loading, the onset potential, half potential and current density all have a certain rise. For example, the catalyst (loading of 500 $\mu \mathrm{g} \mathrm{cm}^{-2}$ ) gives an onset potential at $0.82 \mathrm{~V}$ and a half-wave potential at $0.69 \mathrm{~V}$. Considering that the carbon materials are economical and inexpensive, a large loading can make up the shortage of electrochemically active.

The pathway and kinetic process of the ORR in acidic solution were also evaluated as shown in Fig. 6(e). The peroxide yield on the $\mathrm{AP} / \mathrm{SiO}_{2}$ electrode was found to be very small (less than $3 \%$ ) over the potential range of $0 \mathrm{~V}$ to $0.80 \mathrm{~V}$. The corresponding electron transfer number was thus higher than 3.94. These results also indicated that $\mathrm{AP} / \mathrm{SiO}_{2}$ had a good performance in acidic solution. Further by comparing the performance before and after the 5000 cycles (Fig. 6(f)), to our surprise, $\mathrm{AP} / \mathrm{SiO}_{2}$ even showed much higher durability than Pt/C. Both the onset potential and the half-wave potential are almost no any shift, except for some decrease in diffusion-limited current density. This suggests that the $\mathrm{AP} / \mathrm{SiO}_{2}$ has an excellent electrochemistry performance for ORR.

\section{Conclusions}

From the view of precursor materials, (1) $\mathrm{AP} / \mathrm{SiO}_{2}$ synthesized using small molecules and low-cost material, can greatly reduce the economic cost of the catalyst. (2) The precursor, aminopyrine, acts as both nitrogen and carbon sources at the same time without needing any additional dopants. (3) The nanoscaled template silica can be facially removed by excess amount of sodium hydroxide instead of hydrofluoric acid, thus the catalyst material can be produced in large green quantities. In view of catalyst performance, $\mathrm{AP} / \mathrm{SiO}_{2}$ exhibits high ORR performance (early peak potential and half potential, large current density, high surface area, high porosity) both in the acid and alkaline solution. Meanwhile, $\mathrm{AP} / \mathrm{SiO}_{2}$ shows the perfect resistance to methanol, and cyclic stability.

Since $\mathrm{AP} / \mathrm{SiO}_{2}$ shows a sponge-like uniform structure with a specific surface area of $932.7 \mathrm{~m}^{2} \mathrm{~g}^{-1}$, as a result, the sample exhibits promising ORR activity and stability both in acidic and alkaline solutions. The outstanding electrochemical performance thereby makes it a promising future substitute to commercial $\mathrm{Pt} / \mathrm{C}$ in fuel cell systems.

\section{Acknowledgements}

This work was financially supported by the National Natural Science Foundation of China (U1510120, 21173039); the International Academic Cooperation and Exchange Program of Shanghai Science and Technology Committee (14520721900) and the College of Environmental Science and Engineering, State Environmental Protection Engineering Center for Pollution Treatment and Control in Textile Industry, Donghua University. All the financial supports are gratefully acknowledged. 


\section{References}

1 S. Chu and A. Majumdar, Nature, 2012, 488, 294-303.

2 F. Jaouen, Energy Environ. Sci., 2010, 4, 114-130.

3 W. Gang, K. L. More, C. M. Johnston and Z. Piotr, Science, 2011, 332, 443-447.

4 M. K. Debe, Nature, 2012, 486, 43-51.

5 P. G. Bruce, S. A. Freunberger, L. J. Hardwick and J. M. Tarascon, Nat. Mater., 2012, 11, 19-29.

6 Y. Li, M. Gong, Y. Liang, J. Feng, J. E. Kim, H. Wang, G. Hong, B. Zhang and H. Dai, Nat. Commun., 2013, 4, 1805.

7 K. Gong, F. Du, Z. Xia, M. Durstock and L. Dai, Science, 2009, 323, 760-764.

8 R. J. G. Seungdoo Park and J. M. Vohs, Appl. Catal., A, 2000, 200, 55-61.

9 B. E. Logan, Appl. Microbiol. Biotechnol., 2010, 85, 1665-1671. 10 A. Matthias, K. J. J. Mayrhofer, S. Vojislav, B. B. Blizanac, T. Tada, P. N. Ross and N. M. Markovic, JACS, 2005, 127, 6819-6829.

11 Y. Shao, G. Yin and Y. Gao, J. Power Sources, 2007, 171, 558-566.

12 S. Guo, S. Zhang and S. Sun, Angew. Chem., Int. Ed., 2013, 52, 8526-8544.

13 Z. S. And and S. Holdcroft, Macromolecules, 2004, 37, 20842089.

14 J. J. Shi, X. J. Zhou, P. Xu, J. L. Qiao, Z. W. Chen and Y. Y. Liu, Electrochim. Acta, 2014, 145, 259-269.

15 A. Morozan, B. Jousselme and S. Palacin, Energy Environ. Sci., 2011, 4, 1238.

16 A. Vinu, K. Ariga, T. Mori, T. Nakanishi, S. Hishita, D. Golberg and Y. Bando, Adv. Mater., 2015, 17, 1648-1652.

17 J. Park, Y. Nabae, T. Hayakawa and M.-a. Kakimoto, ACS Catal., 2014, 4, 3749-3754.

18 D. Wang and D. Su, Energy Environ. Sci., 2014, 7, 576.

19 Y. Li, Y. Zhao, H. Cheng, Y. Hu, G. Shi, L. Dai and L. Qu, J. Chem. Soc., 2012, 134, 15-18.

20 J. Liu, X. Sun, P. Song, Y. Zhang, W. Xing and W. Xu, Adv. Mater., 2013, 25, 6879-6883.

21 Z. Chen, D. Higgins, A. Yu, L. Zhang and J. Zhang, Energy Environ. Sci., 2011, 4, 3167-3192.

22 V. Perazzolo, C. Durante, R. Pilot, A. Paduano, J. Zheng, G. A. Rizzi, A. Martucci, G. Granozzi and A. Gennaro, Carbon, 2015, 95, 949-963.

23 K. Elumeeva, N. Fechler, T. P. Fellinger and M. Antonietti, Mater. Horiz., 2014, 1, 588-594.

24 M. J. Wu, E. G. Zhang, Q. P. Guo, Y. Z. Wang, J. L. Qiao, K. X. Li and P. C. Pei, Appl. Energy, 2016, 175, 468-478.

25 M. Wu, J. Qiao, K. Li, X. Zhou, Y. Liu and J. Zhang, Green Chem., 2016, 18, 2699-2709.

26 M. Favaro, L. Ferrighi, G. Fazio, L. Colazzo, C. Di Valentin, C. Durante, F. Sedona, A. Gennaro, S. Agnoli and G. Granozzi, ACS Catal., 2015, 5, 129-144.
27 V. Perazzolo, E. Grądzka, C. Durante, R. Pilot, N. Vicentini, G. A. Rizzi, G. Granozzi and A. Gennaro, Electrochim. Acta, 2016, 197, 251-262.

28 W. Xia, J. Masa, M. Bron, W. Schuhmann and M. Muhler, Electrochem. Commun., 2013, 13, 593-596.

29 H. Peng, Z. Mo, S. Liao, H. Liang, L. Yang, F. Luo, H. Song, Y. Zhong and B. Zhang, Sci. Rep., 2013, 3, 65.

30 G. Wang and P. Zelenay, Acc. Chem. Res., 2013, 46, 18781889.

31 J. Zhang, D. He, H. Su, X. Chen, M. Pan and S. Mu, J. Mater. Chem. A., 2014, 2, 1242-1246.

32 H. W. Liang, W. Wei, Z. S. Wu, X. Feng and K. Mullen, J. Am. Chem. Soc., 2013, 135, 16002-16005.

33 L. Zhang, J. Kim, E. Dy, S. Ban, K.-c. Tsay, H. Kawai, Z. Shi and J. Zhang, Electrochim. Acta, 2013, 108, 480-485.

34 R. Li, A. Cao, Y. Zhang, G. Li, F. Jiang, S. Li, D. Chen, C. Wang, J. Ge and C. Shu, ACS Appl. Mater. Interfaces, 2014, 6, 20574-20578.

35 S. Yang, X. Feng, X. Wang and K. Mullen, Angew. Chem., Int. Ed., 2011, 50, 5339-5343.

36 G. Wu, C. M. Johnston, N. H. Mack, K. Artyushkova, M. Ferrandon, M. Nelson, J. S. Lezama-Pacheco, S. D. Conradson, K. L. More, D. J. Myers and P. Zelenay, J. Mater. Chem., 2011, 21, 11392.

37 Y. Zhao, K. Watanabe and K. Hashimoto, J. Am. Chem. Soc., 2012, 134, 19528-19531.

38 H. Zhang, Y. Wang, D. Wang, Y. Li, X. Liu, P. Liu, H. Yang, T. An, Z. Tang and H. Zhao, Small, 2014, 10, 3371-3378.

39 L. Lai, J. R. Potts, D. Zhan, L. Wang, C. K. Poh, C. Tang, H. Gong, Z. Shen, J. Lin and R. S. Ruoff, Energy Environ. Sci., 2012, 5, 7936.

40 X. Ge, A. Sumboja, D. Wuu, T. An, B. Li, F. W. T. Goh, T. S. A. Hor, Y. Zong and Z. Liu, ACS Catal., 2015, 5, 46434667.

41 Z. S. Wu, L. Chen, J. Liu, K. Parvez, H. Liang, J. Shu, H. Sachdev, R. Graf, X. Feng and K. Mullen, Adv. Mater., 2014, 26, 1450-1455.

42 Y. Zhang, X. Zhuang, Y. Su, F. Zhang and X. Feng, J. Mater. Chem. A, 2014, 2, 7742.

43 W. Wei, H. Liang, K. Parvez, X. Zhuang, X. Feng and K. Mullen, Angew. Chem., 2014, 53, 1570-1574.

44 M. Favaro, F. Carraro, M. Cattelan, L. Colazzo, C. Durante, M. Sambi, A. Gennaro, S. Agnoli and G. Granozzi, J. Mater. Chem. A, 2015, 3, 14334-14347.

45 Y. Tan, C. Xu, G. Chen, X. Fang, N. Zheng and Q. Xie, Adv. Funct. Mater., 2012, 22, 4584-4591.

46 L. Wang, A. Ambrosi and M. Pumera, Angew. Chem., Int. Ed., 2013, 52, 13818-13824.

47 X. J. Zhou, P. Xu, L. Xu, Z. Y. Bai, Z. W. Chen, J. L. Qiao and J. J. Zhang, J. Power Sources, 2014, 260, 349-356. 